\section{A emergência das doenças \\ emergentes e as doenças \\ infecciosas emergentes e \\ reemergentes no Brasil}

The emergence of emerging diseases

and emerging and reemerging

infectious diseases in Brazil

\section{Resumo}

$\mathrm{O}$ artigo discute a emergência do conceito de doenças infecciosas emergentes e reemergentes. Postula-se que o conceito surge frente às limitações da teoria da transição epidemiológica em explicar as tendências recentes da morbidade e mortalidade. São discutidas as bases da teoria da transição epidemiológica e as razões de sua superação. Em seguida, são apresentados o conceito de doenças emergentes e reemergentes, os fatores relacionados à emergência das doenças infecciosas e as principais ocorrências no Brasil. Por fim, são abordados os desafios colocados pela emergência e reemergência das doenças infecciosas, e propostas para o seu enfrentamento.

Palavras-chave: Epidemiologia. Doenças infecciosas emergentes e reemergentes, Brasil. 
Abstract

This article discusses the emergence of the concept of emerging and reemerging infectious diseases. It argues that the concept surfaces due to the limits of the epidemiologic transition theory in explaining the current trends in morbidity and mortality. The bases of the epidemiologic transition theory are discussed, as well as the reasons for its limits. Then, the concept of emerging and reemerging infectious diseases, the factors related to them, and the major episodes of emergence and reemergence of diseases in Brazil are presented. Finally, the article discusses the challenges brought by the emergence and reemergence of infectious diseases, and the proposals to face them.

Keywords: Epidemiology. Emerging and reemerging infectious diseases, Brazil.

\section{Apresentação}

Nos últimos anos tem-se observado, com cada vez mais espaço, o noticiário na mídia acerca da ocorrência de novos problemas de saúde. Inúmeros são os exemplos: ora as encefalites espongiformes transmissíveis, com suas variantes bovina, ovina e humana, na Europa; o aparecimento da encefalite do Nilo Ocidental em Nova Iorque e em outros estados da costa atlântica norte-americana; a volta do Ebola, mais uma vez no Congo, e também em outros países africanos; a "gripe das galinhas” em Hong Kong, China, dentre muitos outros em escala internacional. No Brasil, de forma semelhante, não são poucos os exemplos. A dengue segue sua marcha, chegando agora à cidade de São Paulo, uma das poucas grandes metrópoles do país ainda poupada pela epidemia; a febre amarela "volta” em 2000 a Goiás, e ressurge em Minas Gerais, muito próxima à capital do estado, em 2001; o calazar surge no estado de São Paulo, onde nunca antes havia sido detectado; uma epidemia de nefrite é detectada em uma pequena cidade no centro-oeste mineiro; aglomerados de óbitos por febres hemorrágicas desconhecidas são descritos em localizações tão diferentes quanto Santos - SP, Japerí-RJ, Natal-RN; Pancas - ES e RecifePE. Mais recentemente, o mundo entra em pânico ante a ameaça do uso de microrganismos como armas de guerra.

Todas essas ocorrências já têm inclusive um nome, são as doenças infecciosas emergentes e reemergentes. Mas o que de fato há de novo nesses fenômenos? Estaria mesmo ocorrendo uma alteração dos perfis de morbidade e mortalidade em nível mundial? O que há de comum entre eventos aparentemente tão díspares? Estaria realmente acontecendo uma volta das epidemias e pestes já relegadas aos livros de história? Existiriam mesmo as doenças infecciosas emergentes e reemergentes? Essas indagações vêm perpassando a mente dos leitores mais críticos, e não apenas dos leigos, como também de grande parte dos profissionais de saúde, que se questionam sobre o que de fato está acontecendo. 
Sem a pretensão de esgotar as questões acima elencadas, o presente artigo propõese a discutir a emergência do conceito de doenças emergentes e reemergentes na epidemiologia, seus pressupostos, e os problemas e desafios colocados pelas doenças infecciosas para a sociedade, em particular para aqueles setores envolvidos com sua investigação, prevenção, tratamento e controle.

Postula-se que o conceito - doenças emergentes e reemergentes - emerge frente às limitações do paradigma hegemônico da teoria da transição epidemiológica em explicar um novo quadro de morbimortalidade, especialmente a emergência da epidemia de HIV/aids nos países centrais. Em seguida examinam-se os pressupostos que embasam a proposição da emergência e reemergência das doenças infecciosas. Por fim, apresenta-se o quadro brasileiro quanto à emergência e reemergência destas doenças, e discutem-se os desafios por elas colocados para a pesquisa e para os serviços de saúde, voltados à sua detecção, diagnóstico, terapêutica, prevenção e controle.

\section{A teoria da transição epidemiológica e as doenças infecciosas emergentes}

De acordo com a teoria da transição epidemiológica, em paralelo à transição demográfica, representada pela queda da mortalidade e natalidade e aumento da expectativa de vida das populações humanas, estaria ocorrendo também um processo de mudança nos padrões de adoecimento e morte das populações. Nesse processo, as doenças degenerativas e "produzidas pelo homem" teriam deslocado as doenças infecciosas do lugar de principais causas de mortalidade ${ }^{1}$. Na realidade, este autor sistematiza um conjunto de idéias que naquele momento já se haviam tornado hegemônicas. Segundo ele, a teoria da transição epidemiológica se fundamentaria em cinco proposições básicas:

- a mortalidade seria o fator fundamental na dinâmica das populações, o cresci- mento populacional que se observou após a Era Moderna, especialmente a partir do século XVII seria decorrente fundamentalmente da queda da mortalidade;

- durante a transição, uma mudança de longo prazo teria ocorrido, com a substituição das doenças infecciosas e parasitárias pelas doenças degenerativas e causas externas, enquanto principais causas de morbimortalidade. Este processo teria ocorrido em três estágios sucessivos: a "idade das pestilências e fome", a "idade das pandemias reincidentes" e finalmente a "idade das doenças degenerativas";

- durante a transição, as mudanças mais profundas no padrão de morbimortalidade seriam experimentadas pelas crianças e mulheres jovens;

- as mudanças que caracterizam a transição epidemiológica estariam intimamente associadas com a transição demográfica e sócioeconômica; constituindo em conjunto o "complexo de modernização";

- variações peculiares no padrão, ritmo, determinantes e conseqüências das mudanças populacionais diferenciariam os três modelos básicos da transição epidemiológica, o modelo "clássico", exemplificado pelo Reino Unido, Suécia e Estados Unidos, no qual já na duas primeiras décadas do século $\mathrm{XX}$ as doenças degenerativas haviam substituído as infecciosas como principais causas de mortalidade; o modelo "acelerado", cujo exemplo mais notável seria o Japão, no qual o mesmo processo do modelo clássico teria ocorrido, apenas um pouco mais tardiamente, porém com maior rapidez; e por fim o modelo "contemporâneo/atrasado”, representado pelos países nos quais a transição epidemiológica é ainda mais recente ou ainda não se completou ${ }^{2}$.

Em publicação posterior, o autor indica pequenos adendos à teoria, admitindo um quarto modelo de transição, o modelo "transitório”, que seria uma variante do terceiro, 
representado principalmente por países da Ásia, nos quais em anos recentes estaria ocorrendo um movimento muito rápido em direção à superação das diferenças entre eles e os países do modelo clássico, tendo como principais exemplos a Coréia, Singapura e Taiwan. $\mathrm{O}$ autor admite também, já em resposta às críticas, que as doenças infecciosas não desapareceram totalmente como causas de morte (pneumonias, bronquites, influenza), nem de morbidade (doenças sexualmente transmissíveis) ${ }^{3}$, mas que estas constatações não comprometeriam o sentido geral da teoria da transição epidemiológica, uma seqüência linear e "natural" de etapas, que pode variar em seu ritmo, mas com uma direção clara e estabelecida da substituição das doenças infecciosas e parasitárias pelas crônicodegenerativas e causas externas como mais importantes causas de mortalidade e morbidade das populações humanas.

Ao tentarem analisar a situação da América Latina, alguns autores começaram a se deparar com as limitações da teoria da transição epidemiológica. Apesar de ser uma região relativamente homogênea, um quadro mais complexo do que o habitualmente reconhecido pela teoria da transição epidemiológica emerge na análise dos padrões de mortalidade e morbidade do subcontinente. Observa-se um quadro de grande heterogeneidade entre os países e dentro de cada país. Alguns países estariam em uma etapa mais avançada da transição, correspondendo ao modelo atrasado de Omran (Cuba, Costa Rica, Chile), outros estariam apenas iniciando o processo de transição (Haiti, Bolívia, Peru), e outros ainda apresentariam características tão distintas que configurariam um "novo modelo de transição", que teria como exemplos paradigmáticos o México e o Brasil. Três características distinguiriam estes países:

- sobreposição de etapas - doenças infecto-parasitárias e crônico-degenerativas com grande importância absoluta e relativa;

- um movimento de "contra-transição" representado pelo ressurgimento de doenças como a malária, o cólera e a den- gue, com grande importância na morbidade, mas sem grande interferência na mortalidade e

- uma "transição prolongada", pois não há uma expectativa clara de resolução do processo de transição, que cursa com uma exacerbação das desigualdades dentro dos países.

Estas características distinguiriam na América Latina um novo modelo da transição epidemiológica, o "modelo polarizado prolongado"4. Alguns autores, ao analisarem especificamente a situação brasileira, reconhecem as limitações da teoria da transição epidemiológica original, mas seguem o mesmo caminho, ao identificarem um modelo diferente de transição $0^{5,6}$.

Embora com críticas e adendos, a teoria da transição epidemiológica permaneceu como a teoria hegemônica para a explicação das grandes tendências nos processos de adoecimento e morte das populações até meados dos anos noventa. Um episódio que se inicia no começo da década anterior vai no entanto alterar de forma importante este modelo de interpretação. Trata-se do surgimento da epidemia de aids no início da década de oitenta nos Estados Unidos. A emergência da aids pode ser considerada como o fato mais importante no questionamento das bases e na superação da teoria da transição epidemiológica, abrindo caminho para a construção do conceito das doenças infeciosas emergentes e reemergentes. Com a emergência da aids vem a constatação de que o pretenso movimento de eliminação das doenças infecciosas indicado pela teoria da transição epidemiológica nem sempre se verificava, e mais, que os mesmos fatores relacionados ao progresso, ao desenvolvimento socioeconômico e a modernidade, que seriam os determinantes da transição epidemiológica, também poderiam determinar processos na direção inversa, propiciando o surgimento e a disseminação de novas e velhas doenças infecto-parasitárias.

Em 1989, nos Estados Unidos, realiza-se uma primeira conferência sobre viroses emergentes, promovida pelo Instituto Nacional de Alergia e Doenças Infecciosas. Neste 
evento, ficou claro que o foco de preocupações não deveria se restringir às viroses, mas deveria abarcar as doenças infecciosas como um todo. Dois anos depois, o Instituto de Medicina da Academia Nacional de Ciências dos EUA organizou um comitê multidisciplinar com o objetivo de estudar as "ameaças microbianas à saúde dos Estados Unidos". Em 1992, este comitê publica suas conclusões em um relatório que é considerado a primeira publicação com o enfoque na emergência e reemergência das doenças infeciosas e parasitárias?

\section{A emergência e reemergência das doenças infecciosas}

Doenças infecciosas emergentes e reemergentes são aquelas cuja incidência em humanos vem aumentando nas últimas duas décadas ou ameaça aumentar num futuro próximo ${ }^{8}$.

Ao tentar especificar mais esta noção, verificam-se dois principais focos de atenção: o surgimento ou identificação de novos problemas de saúde e novos agentes infecciosos; e a mudança no comportamento epidemiológico de doenças já conhecidas, incluindo a introdução de agentes já conhecidos em novas populações de hospedeiros suscetíveis.

Um número muito grande de fatores estariam envolvidos na determinação da emergência e reemergência de doenças infecciosas. No sentido de facilitar sua discussão, esses fatores podem ser agrupados em sete grandes grupos:

- fatores demográficos;

- fatores sociais e políticos;

- fatores econômicos;

- fatores ambientais;

- fatores relacionados ao desempenho do setor saúde;

- fatores relacionados às mudanças e adaptação dos microrganismos e

- manipulação de microrganismos com vistas ao desenvolvimento de armas biológicas.

Em seguida serão discutidos resumidamente cada um desses grupos de fatores, buscando-se inclusive demonstrar exemplos de situações de emergência e reemergência de doenças nas quais estes fatores tiveram papel importante. Convém ressaltar que, na maioria das situações, múltiplos fatores atuam simultaneamente em sua determinação.

\section{Fatores demográficos}

A população mundial continua a crescer, a um ritmo de aproximadamente 70 milhões ao ano. Já chegamos aos 6 bilhões de habitantes no planeta. A maior parte deste incremento se dá hoje nos países subdesenvolvidos, e nesses países verifica-se uma crescente urbanização. Hoje estima-se que $50 \%$ da população mundial vive nas cidades. A estimativa para o ano 2000 é da existência de 425 cidades com mais de 1 milhão de habitantes. No mundo subdesenvolvido, esta urbanização significa aglomeração intensa, com populações grandes vivendo em espaço reduzido; saneamento inadequado, tanto em relação ao abastecimento da água, quanto aos sistemas de esgotamento sanitário e destinação de resíduos sólidos; habitação precária; proliferação de fauna sinantrópica; falta de infraestrutura urbana e agressão ao meio ambiente. Estes fatores criam as condições adequadas para a proliferação e disseminação de determinados agentes, seus vetores e reservatórios. A emergência da dengue, enquanto uma pandemia nos países subdesenvolvidos, é o exemplo mais eloqüente da influência dos fatores demográficos e da forma de urbanização desses países na reemergência de doenças. Por outro lado, nos países desenvolvidos o aumento da expectativa de vida faz com que uma população cada vez mais idosa se torne mais suscetível a determinados agentes infecciosos, que podem levar a quadros de maior gravidade entre os mais velhos. As epidemias de gripe (influenza), por exemplo, tendem a acometer os idosos com quadros mais graves. Na emergência da doença pelo vírus do Nilo Ocidental em Nova Iorque, os idosos foram o grupo mais atingido e no qual a doença se manifestou em sua forma mais severa ${ }^{9,10}$. Além disso, a queda da nata- 
lidade nos países desenvolvidos leva à necessidade da vinda de imigrantes para o mercado de trabalho. A imigração também contribui para a emergência de doenças infecciosas, e cria um fluxo contínuo de viajantes internacionais, o que também pode contribuir para a disseminação de doenças. As viagens constituem uma força importante na emergência de doenças. $\mathrm{O}$ atual volume, rapidez e alcance das viagens não tem precedentes na história. Estima-se que mais de 500 milhões de pessoas fazem anualmente viagens internacionais. Existem cerca de 70 milhões de imigrantes nos países desenvolvidos, originários dos países subdesenvolvidos. Os viajantes podem transportar os agentes infecciosos, seus vetores, e ainda hábitos e tecnologia que podem propiciar a emergência de doenças ${ }^{11}$.

\section{Fatores sociais e políticos}

As guerras, levando a grandes deslocamentos populacionais de massa, com a geração de populações de refugiados sobrevivendo em condições degradantes, também levam à criação de condições adequadas à emergência e reemergência de doenças. Estima-se a existência de 20 a 30 milhões de refugiados de guerra. No Zaire, em 1994, cerca de 50 mil refugiados da guerra de Ruanda morreram nos primeiros meses nos campos de refugiados, de cólera e diarréia por Shigella dysenteriae. A própria emergência da epidemia de HIV/aids tem sido associada por muitos pesquisadores com as guerras. De possível origem zoonótica, o HIV teria passado para a espécie humana em populações rurais remotas da África Central, e disseminado-se com os grandes deslocamentos populacionais decorrentes dos conflitos armados naquela região ${ }^{12}$.

A heterogeneidade no desenvolvimento socioeconômico também constitui um fator de estímulo às migrações internas e internacionais, também gerando pressão para a disseminação de doenças. As mudanças comportamentais, decorrentes da urbanização, da incorporação das mulheres ao mercado de trabalho, do surgimento de méto- dos contraceptivos de maior eficácia, a maior liberdade sexual, e ainda a disseminação do uso de substâncias psicoativas, muitas vezes por via injetável, contribuíram para a reemergência e a disseminação de várias doenças sexualmente transmissíveis, em especial a gonorréia, a sífilis, as infecções por Chlamydia trachomatis e as hepatites B e C, além de desempenharem um papel de destaque na emergência da epidemia de HIV/ aids.

\section{Fatores econômicos}

A história nos demonstra o papel dos fatores econômicos, em especial o comércio internacional, na emergência e na disseminação de doenças. O início do comércio entre a Ásia e a Europa, pela rota da seda, trouxe os ratos e a peste. O comércio de escravos, a dengue e a febre amarela e o seu vetor para as Américas. O cólera saiu da Índia para o mundo, em pandemias sucessivas. Atualmente, dada a rapidez das viagens internacionais e o grande incremento do comércio internacional, a disseminação de doenças por esta via é muito mais fácil e rápida. A reemergência do cólera na América do Sul em 1990 foi relacionada à água de lastro de navios fazendo a rota Ásia-Peru; a disseminação dos hantavírus, possivelmente trazidos pelos roedores a bordo de navios; a disseminação do Aedes albopictus, pelo comércio de pneus usados, são alguns dos exemplos recentes do papel do comércio internacional na emergência e reemergência de doenças ${ }^{13}$. Merece atenção especial a produção e comercialização de alimentos enquanto fator associado à emergência de doenças. A ocupação agrícola de novas áreas tem sido associada à emergência das hantaviroses com síndrome pulmonar (SPH). No Brasil, a ocorrência da SPH está associada às culturas de cana de açúcar (em São Paulo) e arroz (no Maranhão). Na Argentina, a emergência da febre hemorrágica pelo vírus Junín relacionou-se à ocupação agrícola do pampa. Novas tecnologias e práticas agropecuárias também vêm contribuindo para a emergência de doenças. O uso de carcassas 
de animais para a produção de ração levou à ocorrência da epizootia de encefalite espongiforme bovina no Reino Unido e em outros países europeus, zoonose possivelmente associada ao aumento da ocorrência de casos humanos de encefalites espongiformes ${ }^{14}$. A produção em escala industrial e a própria industrialização de produtos agropecuários têm levado à ocorrência de inúmeros surtos de doenças transmitidas por alimentos (DTA), que agora têm o potencial de atingir um número cada vez maior de pessoas em regiões geográficas cada vez mais distantes. Laticínios contaminados por Salmonella enteritidis já levaram a surtos que atingiram mais de 250.000 pessoas nos EUA. A contaminação de ovos e aves com Salmonella também tem ocasionado inúmeros surtos ${ }^{15}$. Higiene e práticas inadequadas em açougues e indústrias de carne têm levado a um aumento da ocorrência de infecções por Escherichia coli $\mathrm{O} 157 \mathrm{H} 7 \mathrm{e}$ da síndrome hemolítico-urêmica (SHU). As migrações, por sua vez, contribuem para a disseminação de novos hábitos alimentares, que podem estar associados à ocorrência de surtos de DTA, como um surto de cólera na comunidade tailandesa em Maryland, EUA, associado ao leite de coco importado da Tailândia ${ }^{16}$.

\section{Fatores ambientais}

Grandes projetos de engenharia, como represas, rodovias, expansão da fronteira agrícola, têm sido freqüentemente associados à emergência e reemergência de doenças. No Brasil, por exemplo, a construção da represa de Itaipu propiciou as condições necessárias à emergência da malária no sul do país. A ocupação da fronteira oeste a partir do final dos anos setenta, com a migração de populações de regiões não endêmicas, levou ao recrudescimento da malária no Brasil. A ocupação de novas áreas tem levado à expansão da área de transmissão da leishmaniose tegumentar americana no nosso país. O reflorestamento e a ocupação humana nas proximidades de áreas reflorestadas levaram à emergência da doença de
Lyme nos EUA ${ }^{13,17}$. À proximidade entre seres humanos e animais, principalmente aves e suínos na China, se tem atribuído a emergência de novos vírus da gripe. A importação clandestina de fauna exótica foi provavelmente responsável pela introdução do vírus do Nilo Ocidental em Nova Iorque ${ }^{9}$ Sua disseminação por quase toda a costa atlântica dos EUA, já chegando ao Caribe, está ocorrendo pela migração natural das aves. As grandes mudanças climáticas que vêm ocorrendo, não apenas em escala nacional, mas em escala mundial, com o aquecimento global, perecem ter influência importante na emergência e reemergência de doenças, em especial das doenças transmitidas por vetores. Secas e inundações, também parte do mesmo fenômeno, contribuem para a emergência e disseminação de doenças como o cólera e a leptospirose.

\section{Fatores relacionados ao setor saúde}

De maneira geral, a expansão da cobertura de serviços da saúde e a incorporação de novas tecnologias de diagnóstico vêm permitindo a identificação de novos agentes infecciosos e quadros sindrômicos a eles associados. A incorporação das técnicas de biologia molecular à investigação das doenças transmissíveis vem permitindo um grande avanço nos conhecimentos e possibilitando a abertura de toda uma nova abordagem, a da identificação de microrganismos como co-fatores em várias doenças crônicas. Entre outros exemplos, o HTLV e a leucemia de células T do adulto, o HSV 8 e o Sarcoma de Kaposi, o Helycobecter pylorie a úlcera gástrica, o HPV e o câncer cervical. Em uma outra perspectiva, as falhas do setor saúde têm contribuído, em muitas situações para a emergência, reemergência e disseminação de doenças. Falhas no controle do sangue e hemoderivados contribuíram para a disseminação do HIV e outros agentes em vários países do mundo; da mesma forma, práticas de esterilização precárias contribuíram para a disseminação do HIV na Europa Oriental e África, e mesmo o primeiro surto da febre hemorrágica pelo vírus 
Ebola teve sua disseminação potencializada pelos serviços de saúde. A falência da saúde pública em muitos países, notadamente na Europa Oriental vem contribuindo para a reemergência de várias doenças, como difteria, coqueluche e tuberculose. Falhas dos programas de vacinação levaram à reemergência da poliomielite no Continente Americano, com a reversão da virulência do vírus vacinal após sua circulação em população não vacinada no Haiti e na República Dominicana ${ }^{16}$. Por outro lado, o sucesso de alguns programas de imunização vem acarretando a emergência de eventos adversos às vacinas até então desconhecidos, como a ocorrência de casos de febre amarela vacinal no Brasil e nos EUA ${ }^{18}$, e a seleção de cepas "escapees", vírus e bactérias "fugitivos", mutantes ou cepas selecionadas para os quais as vacinas não protegem, como já se observou para a coqueluche e hepatite $\mathrm{B}^{19,20}$.

\section{Fatores relacionados à mudança e à adaptação dos microrganismos}

Cada espécie microbiana apresenta sua própria taxa de mutações, que se relaciona à quantidade de pares de bases em seugenoma e a sua velocidade de reprodução. As variações naturais e mutações podem levar à emergência de doenças, como no caso da febre purpúrica brasileira, quando uma variante da bactéria Haemophilus influenzae biogrupo aegyptius tornou-se invasiva pela incorporação de um plasmídio ${ }^{21,22}$. Os hospitais concentram três características que os tornam sítios particularmente vulneráveis à emergência de novos agentes resistentes às drogas disponíveis: vítimas de infecções graves, pessoas mais suscetíveis e uso generalizado de antibióticos. A pressão seletiva gerada pelo uso dos antibióticos e de outros agentes antimicrobianos favorece a sobrevivência dos mutantes, que resistem às drogas. O grande desenvolvimento da indústria farmacêutica, com a oferta constante de novos agentes antimicrobianos vem contribuindo para tornar os hospitais locais privilegiados para a emergência de superbactérias, vírus e fungos. Além disso, a amplia- ção do uso de aparelhos e instrumentos também contribui para o aumento da incidência de infecções hospitalares. Sondas e catéteres são os veículos de grande parte das infecções nosocomiais. As infecções hospitalares constituem uma dos principais problemas de doenças infecciosas emergentes nos países desenvolvidos e em grande parte dos subdesenvolvidos. Representam uma proporção considerável dos custos da assistência hospitalar. Por outro lado, as falhas na adesão ao tratamento são as responsáveis pela seleção de linhagens resistentes do Micobacterium tuberculosis, do HIV e de outros microrganismos.

\section{Manipulação de microrganismos com vistas ao desenvolvimento de armas biológicas}

A idéia do uso das doenças transmissíveis enquanto armas de guerra não é nova, mas apenas durante o século XX, com o desenvolvimento da microbiologia, é que se tornou factível a experimentação do desenvolvimento de microrganismos como arma de guerra. Alemanha, Japão, União Soviética e EUA, já no período da II Guerra Mundial, desenvolveram programas de armas biológicas. Posteriormente, pelo menos as duas superpotências do pós-guerra e talvez mais uma dúzia de países tenham desenvolvido programas semelhantes. Dado o sigilo que encobre essas iniciativas, é difícil fazer uma avaliação mais concreta acerca do avanço dessas experiências. Com a fuga do seu vice-diretor para os EUA em 1992 e a publicação do livro dele em 2000, vieram à tona várias informações acerca do programa soviético de armas biológicas. A União Soviética desenvolveu um programa de larga escala de pesquisa, desenvolvimento, produção, armazenamento e "distribuição" de armas biológicas. A "Biopreparat”, agência governamental que executava o programa, chegou a ter mais de 40.000 funcionários em 60 localidades. Entre outras doenças e agentes infecciosos pesquisados para uso enquanto armas estão a varíola (Orthopoxvirus), o antraz (Bacillus antracis); a tularemia (Francisella tularensis), 
o mormo (Burkholderia mallei), a meliloidose (Burkholderia pseudomallei), a peste (Yersinia pestis), a brucelose (espécies do gênero Brucella), os filovírus (Ebola, Marburg) e o arenavírus (Machupo). Dentre outros relatos, merece destaque o acidente ocorrido em 1979 na cidade de Sverdlovsk, com o vazamento de aerossóis contendo o bacilo do antraz de uma dos instalações da Biopreparat, episódio no qual foram reconhecidos 77 casos entre habitantes da cidade, com uma letalidade de $90 \%{ }^{23}$.

\section{As doenças emergentes e reemergentes no Brasil}

No Brasil, o modelo da transição epidemiológica nunca foi aplicável com perfeição. Em que pese uma marcante diminuição do peso relativo das doenças infecciosas e parasitárias enquanto causas de mortalidade, diminuição esta relacionada principalmente à redução das doenças imunopreveníveis e das diarréias, persistem marcantes desigualdades regionais e sociais, com a existência de aglomerados populacionais nos quais os perfis de mortalidade pouco se alteraram nas últimas décadas.

Além disso, embora se venha observando uma tendência de redução proporcional do peso das doenças infecciosas enquanto causas de morte, esta tendência não se verifica quando se analisam os dados de morbidade. Mesmo considerando as limitações de cobertura e qualidade destes últimos, constata-se que, à exceção das doenças imunopreveníveis, as demais doenças infecciosas e parasitárias vêm se mantendo num patamar quase constante nas últimas duas décadas, representando cerca de $10 \%$ das causas de internações hospitalares na rede hospitalar pública e contratada pelo SUS anualmente. Ao discutir esta situação, Barreto et al., não sem alguma ironia, afirmam existir no Brasil não apenas as doenças emergentes e reemergentes, mas também as "permanecentes" 24 .

Embora reconhecendo que as doenças infecciosas e parasitárias sempre mantiveram sua importância no Brasil, não se pode também banalizar a questão da sua emergência e reemergência no país. Sim, elas se mantêm em um patamar relativamente constante enquanto causas de internação hospitalar, porém sua composição interna se modifica nas últimas duas décadas, além da verificação da emergência e reemergência de doenças que apenas excepcionalmente demandam internação hospitalar.

Devemos também reconhecer que grande parte das condições e fatores relacionados à emergência e reemergência das doenças infecciosas e parasitárias estão presentes no nosso país, e que o seu processo de emergência e reemergência continua a ocorrer. Muitos são os exemplos:

- A epidemia de HIV/aids emerge em nosso país quase simultaneamente à América do Norte, Europa e África. Atinge o seu pico em meados da década passada, e vem se mantendo em um patamar elevado nos últimos anos. Como exemplo paradigmático da emergência, a epidemia de aids não pára de se modificar internamente, atingindo diferentes grupos populacionais vulneráveis a cada momento.

- O cólera chega ao Brasil no verão de 1991/92. A epidemia atinge seu pico em 1993 com mais de 60 mil casos notificados. A partir de 1995 observa-se um declínio acentuado em sua ocorrência, que adquire contornos de endemicidade, restrita a alguns estados do Nordeste brasileiro, com a ocorrência de picos epidêmicos localizados e esporádicos, no próprio Nordeste e eventualmente em outras regiões do país, como no Paraná, em 1998.

- Adengue emergiu em 1982 no Brasil, com uma epidemia localizada em Boa Vista, Roraima, possivelmente trazida da Venezuela, país que faz fronteira com aquele estado brasileiro. Após um silêncio de quatro anos, uma nova epidemia voltou a ocorrer, desta vez no Rio de Janeiro, e daí por diante espalhou-se por quase todo o país. Apenas dois estados ainda não registraram casos autóctones. Três tipos de vírus circulam simultanea- 
mente. O país vive mais uma onda epidêmica, possivelmente relacionada à emergência do Den III. Epidemias de grandes proporções foram registradas na maioria das grandes cidades do país. $\mathrm{O}$ número de casos notificados tem chegado à casa das centenas de milhares anualmente. Chama a atenção o pequeno número de casos de febre hemorrágica da dengue (FHD) registrados no Brasil, dadas as dimensões da nossa epidemia, quando comparada à ocorrência de FHD em outros países ${ }^{25}$.

- Embora um problema localizado, restrito quase que integralmente à Região Amazônica, a malária reemerge com vigor nas últimas duas décadas. A ocupação da Amazônia, com população migrante de áreas indenes, e a intensa urbanização da população daquela região, levaram à reversão da tendência de queda na ocorrência de malária que se vinha observando até a década de setenta. Hoje a malária ocorre em zonas periurbanas e continua a ter uma grande importância nos novos assentamentos rurais naquela região.

- Sem o grande impacto dos quatro problemas acima destacados, um número expressivo de outras doenças infecciosas e parasitárias vem emergindo ou reemergindo no Brasil nas últimas duas décadas. Entre as parasitárias, merece destaque a expansão geográfica da transmissão das leishmanioses, tanto a tegumentar quanto o calazar, e também da esquistossomose. Entre as virais, a SPH emerge em São Paulo, em 1993, e desde então sua ocorrência vem sendo detectada em cada vez mais regiões do país. A febre amarela reemerge em 2000, com surto na Região Centro-Oeste, que se expande até São Paulo, ao sul, e à Bahia, a leste, e volta em 2001, com novo surto no oeste de Minas Gerais. Já entre as bacterianas deve-se ressaltar a emergência da leptospirose como um problema nacional, com a ocorrência de epidemias em quase todas as grandes cidades brasileiras, e o incremento na detecção de surtos de DTA, inclusive com o registro de eventos inusitados como a epidemia de nefrite pós infecção pelo Streptococcus zooepidemicus em Minas Gerais $^{26}$. O Quadro 1 resume os principais episódios de emergência e reemergência de doenças infecciosas registrados no Brasil.

\section{Os desafios colocados pela emergência e reemergência das doenças infecciosas}

Como coloca Drotman, dos CDC, "a concepção de que as doenças infecciosas emergem e reemergem não é nova, nem tampouco a busca por suas causas. As doenças infecciosas vêm emergindo pelo menos desde que os humanos habitam a Terra"27. Parece até uma noção elementar, baseada na tríade ecológica (agente, hospedeiro e ambiente), de que o processo de mudança contínuo das interações entre as populações humanas (e seus condicionantes históricos, sociais, políticos, econômicos e culturais), animais e de microrganismos, e destas todas com o meio ambiente modificado pela ação humana, continua e vai continuar a produzir condições que irão propiciar a emergência, reemergência, e até eventualmente o desaparecimento de doenças infecciosas e parasitárias. No entanto, a noção simples e equivocada oferecida pela teoria da transição epidemiológica tornou-se hegemônica durante boa parte do século passado, o que acabou por contribuir para o despreparo de profissionais e serviços de saúde, bem como das sociedades enquanto um todo, no enfrentamento da emergência e reemergência das doenças infecciosas.

Faz-se então necessário discutir os desafios colocados à saúde pública pela emergência e reemergência das doenças infecciosas e parasitárias, e quais as melhores formas de enfrentá-los.

Resumidamente, poder-se-ia dizer que a principal medida a ser desenvolvida seria o reforço da nossa capacidade de detecção das doenças emergentes e reemergentes. Em outras palavras, o reforço e a revalorização 
Quadro 1 - Alguns Episódios de Doenças Emergentes e Reemergentes no Brasil Chart 1 - Some episodes of emerging and reemerging diseases in Brazil

\begin{tabular}{|c|c|c|}
\hline Ano & Doença/ Ocorrência & Local \\
\hline $1970-73$ & Epidemia de encefalite - vírus Rocio & Vale do Ribeira/São Paulo \\
\hline 1975 & 1a detecção de Rotavirus & Belém/PA \\
\hline 1982 & 1a epidemia de dengue & Boa Vista/ RR \\
\hline 1983 & 1 os casos de AIDS & São Paulo/SP \\
\hline 1985 & 1 surto de febre purpúrica brasileira & Promissão/SP \\
\hline 1986 & Dengue & Rio de Janeiro/RJ \\
\hline 1990 & Vírus Sabiá & São Paulo/SP \\
\hline 1991 & Cólera & Vale do Solimões/AM \\
\hline 1991 & Isolado Coccidioidis immitis & Região central do Piauí \\
\hline 1993 & 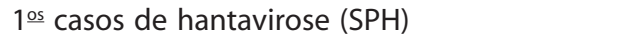 & Juquitiba/SP \\
\hline 1995 & Doença pelo vírus Ilhéus & Estado de São Paulo \\
\hline 1997 & Calazar em zonas urbanas & Estados do Nordeste \\
\hline 1997 & 1ㅇs casos de Enterococcus resistentes & São Paulo/SP \\
\hline 1998 & $\begin{array}{l}\text { Nefrite epidêmica pós infecção por } \\
\text { Streptococcus zooepidemicus }\end{array}$ & Nova Serrana/MG \\
\hline 1998 & Surto de parvovirose B 19 & Joaçaba - Herval d'Oeste/SC \\
\hline 1998 & $\begin{array}{l}\text { Aglomerado de óbitos por síndrome } \\
\text { febril hemorrágica - suspeita do vírus } \\
\text { Saint Louis }\end{array}$ & Fortaleza/CE \\
\hline 1998 & Surto de febre maculosa & Estado do Rio de Janeiro, \\
\hline 1998 & Surtos de hantavirose & $\begin{array}{l}\text { Oeste de São Paulo, Triângulo } \\
\text { mineiro, Rio Grande do Sul, }\end{array}$ \\
\hline 1998 & Surtos de febre amarela & $\begin{array}{l}\text { Mucajaí - Alto Alegre/RR, Ilha } \\
\text { do Marajó/PA }\end{array}$ \\
\hline 1998 & Epidemia de gripe - vírus Influenza B & Belém/PA \\
\hline 1999 & $\begin{array}{l}\text { Surto de toxoplasmose aguda / } \\
\text { origem alimentar }\end{array}$ & Taquarituba, Itapeva/SP \\
\hline 1999 & $\begin{array}{l}\text { Aglomerados de óbitos por síndrome } \\
\text { febril hemorrágica - etiologia não esclarecida }\end{array}$ & Natal/RN, Santos/SP, Recife/PE \\
\hline 1999 & $\begin{array}{l}\text { Surto de toxoplasmose aguda em campus } \\
\text { universitário }\end{array}$ & São Carlos/SP \\
\hline 1999 & Surto de vaccínia (Orthopoxvirus) & Cambucí/RJ \\
\hline 2000 & Surto de febre amarela & $\begin{array}{l}\text { Tocantins, Goiás, Bahia, Minas } \\
\text { Gerais, São Paulo }\end{array}$ \\
\hline 2000 & $\begin{array}{l}\text { Aglomerados de óbitos por síndrome } \\
\text { febril hemorrágica - etiologia não esclarecida }\end{array}$ & Pancas/ES, Japerí/RJ \\
\hline 2000 & Calazar & Araçatuba/SP \\
\hline 2001 & Surto de febre amarela & Oeste de Minas Gerais \\
\hline
\end{tabular}

Fontes: adaptado de Gattás, $2000^{33}$; Momen, $1998^{34}$.

Sources: adapted from Gattás, 200033; Momen, $1998^{34}$. 
da vigilância epidemiológica. Esta medida, enunciada dessa forma, parece simples, mas sua execução pode se revelar mais complexa do que aparenta.

Para começar, o aprimoramento da capacidade de detecção das doenças infecciosas emergentes e reemergentes exige a participação dos profissionais da clínica. Médicos, enfermeiros, médicos veterinários, e demais profissionais envolvidos com a assistência, serão os primeiros a receber os casos suspeitos. É necessário então que estes profissionais estejam capacitados a iniciar a sua investigação e conscientes das possíveis implicações da detecção de um caso de uma doença emergente. Isto não é simples, pois a maioria dos profissionais foi e continua a ser formada dentro dos marcos da teoria da transição epidemiológica. Há que se investir na formação dos novos profissionais e na educação continuada dos demais, estimulando sua curiosidade na investigação diagnóstica dos casos suspeitos de doenças infecciosas, buscando o diagnóstico etiológico e tendo clareza da necessidade de investigação epidemiológica e notificação.

Em seguida, há que se pensar no laboratório de saúde pública. Para que seja possível a detecção das doenças emergentes e reemergentes faz-se necessária a existência de uma rede de laboratórios, organizada de forma hierarquizada, com complexidade crescente, com equipamento adequado, suprimento oportuno de insumos, profissionais capacitados e capaz da garantir as condições necessárias de biossegurança. No nosso país, esta rede precisa ir além da já existente rede constituída pelos laboratórios de saúde pública (LACEN) de cada estado e os laboratórios federais, e incluir também os laboratórios universitários, não só os de patologia clínica, microbiologia, parasitologia, virologia e imunologia, mas também os de entomologia, zoologia, ecologia, ornitologia, micologia, medicina veterinária, enfim, de todas as disciplinas que tenham interesse e possam contribuir neste esforço. Não se pode ignorar as experiências vividas. Por ocasião da emergência do vírus do Nilo Ocidental em Nova Iorque, o primeiro sinal de alarme partiu dos veterinários do zoológico do Queens, preocupados com um excesso de mortalidade de aves. $O$ alerta dos veterinários, entretanto, não foi capaz de sensibilizar a vigilância epidemiológica (CDC) que só alguns meses após o surgimento de casos humanos valorizou aquela ocorrência entre aves exóticas de um zoológico ${ }^{28}$. A rede laboratorial de doenças emergentes deve incluir também laboratórios da rede privada que demonstrarem interesse em participar, bem como os laboratórios das forças armadas. Esta rede ampliada, por sua vez, deve reforçar suas relações com as redes internacionais, organizadas pela OPS/OMS, das quais o Brasil já faz parte ${ }^{29,30}$. A questão da biossegurança deve também ocupar lugar de destaque, exigindo uma política nacional de biossegurança que inclua uma rede hierarquizada, com a existência de pelo menos um laboratório de nível máximo de biossegurança no país (P4), e que seja capaz de garantir não apenas a segurança dos profissionais envolvidos na pesquisa, mas também da sociedade enquanto um todo, face a ameaça cada vez mais concreta do bioterrorismo.

O reforço da rede de serviços de vigilância epidemiológica é outra peça fundamental para garantia das condições de enfrentamento das doenças emergentes e reemergentes. A recente descentralização para os municípios das atividades de vigilância e controle de doenças representou a incorporação de um grande número de novos atores nesse processo, por vezes sem o mínimo de capacitação necessária para o trabalho nesse campo. A falta de uma política de recursos humanos, de uma carreira e salários muito baixos, vêm afastando os profissionais deste campo de trabalho. A vigilância epidemiológica é uma ação exclusiva do poder público e enquanto este não estiver convencido da necessidade e da importância de uma rede forte e eficiente de vigilância epidemiológica, e que este fortalecimento passa pela política de recursos humanos, $\mathrm{o}$ país continuará vulnerável a ser surpreendido por surtos e epidemias de doenças emergentes e reemergentes. Os serviços de vigi- 
lância epidemiológica são os elos da corrente formada pelos diferentes atores envolvidos no processo de investigação e controle das doenças transmissíveis, e o seu fortalecimento é que possibilitará a revalorização da epidemiologia descritiva, como coloca Barata $^{31}$, com o desenvolvimento de métodos e técnicas de análise mais modernos e apropriados.

Da mesma forma, o reforço aos serviços e atividades do campo da saúde ambiental, vigilância sanitária e saúde pública veterinária é necessário para o enfrentamento das doenças emergentes. Alguns dos fatores relacionados à emergência de doenças, como por exemplo a fauna sinantrópica, as condições sanitárias dos alimentos e das populações animais podem ser monitorizadas de forma rotineira e eficiente, o que permitiria ao setor saúde antecipar-se à emergência das doenças. Isto exigiria não apenas o reforço dos serviços, mas também a existência de mecanismos ágeis de comunicação entre os diferentes serviços e atores envolvidos.

Uma condição necessária para o funcionamento e aprimoramento da capacidade de resposta nacional à emergência e reemergência de doença é a existência de mecanismos ágeis e eficientes de informação e comunicação. É urgente a implantação de um sistema de informações on line para notificação de doenças, que possa incluir também as emergentes, e que inclua não apenas a rede de serviços responsáveis pela $\mathrm{VE}$, mas também laboratórios, universidades, profissionais interessados etc. Esta rede deve ser complementada pela implantação e/ou ampliação de serviços de boletins informatizados que facilitem a comunicação de ocorrências (como o PROMED, por exemplo), e buscar atingir o maior número possível de serviços e profissionais. A revista do Centro Nacional de Epidemiologia - CENEPI, o Informe Epidemiológico do SUS, que já é a revista científica da área da saúde de maior circulação no país, poderia conferir também mais espaço para a divulgação de informações sobre doenças emergentes e reemergentes, sem a necessidade de se criar, como fizeram os CDC, um periódico específico ${ }^{9,32}$.
Uma estratégia de enfrentamento das doenças emergentes e reemergentes não estaria completa sem o claro envolvimento das universidades e dos institutos de pesquisa, responsáveis pela pesquisa aplicada e básica. Faz-se necessário o diálogo contínuo e a integração entre o setor de pesquisa e os serviços responsáveis pela vigilância e o controle. Áreas como a pesquisa de novas tecnologias de diagnóstico; investigação epidemiológica; pesquisa microbiológica incluindo a biologia molecular; investigação farmacológica e terapêutica; investigação imunológica e de vacinas; e o estímulo à investigação inter-disciplinar; precisam ser incluídas em uma estratégia nacional de enfrentamento da emergência e reemergência de doenças infecciosas e parasitárias.

Nos últimos anos o Ministério da Saúde, através de alguns dos seus órgãos, como Centro Nacional de Epidemiologia/ FUNASA, a Agência Nacional de Vigilância Sanitária e o Programa Nacional de DST e Aids, tem dado passos concretos na direção do fortalecimento da capacidade nacional de resposta à emergência e reemergência de doenças. A participação brasileira nas redes internacionais de vigilância e laboratório de doenças emergentes, o fomento à organização de redes nacionais de vigilância e laboratório para doenças específicas, a formulação de uma política de biossegurança, incluindo a capacitação de pessoal; a parceria com os CDC, especialmente no campo da capacitação de epidemiologistas; a criação de um setor de vigilância ambiental em saúde; a disseminação do Curso Básico de Vigilância Epidemiológica; e mesmo a própria descentralização dos programas de controle de endemias; a celebração de contratos de empréstimo junto ao banco mundial específicos para a vigilância e o controle de doenças; o estímulo ao diálogo com as universidades e instituições de pesquisa, através dos comitês técnicos, bem como do financiamento direto de projetos de pesquisa aplicada, sem dúvida são ações na direção correta. No entanto, tem faltado agilidade na transformação dos planos e projetos em ações concretas. O excesso de burocracia, a 
lentidão na tomada de decisões, a carência de recursos humanos qualificados e a precariedade das estruturas descentralizadas compromete a viabilidade dos projetos.

Pelas características de sua formação social, política, econômica e cultural; por suas peculiaridades geográficas, climáticas e ecológicas, o Brasil reúne as condições necessárias para a emergência e reemergência de doenças infeciosas e parasitárias. Ao mesmo tempo, o país dispõe de uma ampla rede de serviços de saúde, um grande quadro de profissionais, e uma capacidade instalada de pesquisa biomédica capaz de enfrentar este desafio. Cabe ao poder público dotar de mais agilidade os setores envolvidos, estimular o fortalecimento institucional nas diferentes esferas de governo e buscar das parcerias com os serviços, profissionais e instituições envolvidas com o tema, e também cabe à sociedade civil, a organização e pressão para que o país possa melhor se preparar para o enfrentamento da emergência e reemergência das doenças infecto-parasitárias.

\section{Referências}

1. Omran AR. The epidemiologic transition: a theory of the epidemiology of population change. Milbank Mem Fund 1971; Q 49(4): 509-38.

2. Omran AR. A century of epidemiologic transition in the United States. Prev Med 1977; 6; 30-51.

3. Omran AR. The epidemiologic transition theory. A preliminary update. J Trop Ped 1983; 29: 306-16.

4. Frenk J, Frejka T, Bobadilla JL, Stern C et al. La transición epidemiológica em América Latina. Bull Sanit Panam 1991; 111(6): 485-96.

5. Araújo JD. Polarização Epidemiológica no Brasil. Informe Epidemiológico do SUS 1992; 1(2): 5-16.

6. Reichenheim ME, Werneck GL. Adoecer e morrer no Brasil dos anos 80: perspectivas de novas abordagens. In: Guimarães R, Tavares R. Saúde e Sociedade no Brasil anos 80. Rio de Janeiro: Relume-Dumará/ ABRASCO/IMS-UERJ; 1994.

7. Ledeberg J, Shope, RE, Oaks SC (eds.). Emerging infections: microbial threats to health in the United States. Washington: National Academy Press; 1992.

8. CDC - Centres for Disease Control and Prevention. Addressing emerging infectious disease threats: a prevention stategy for the United States. Atlanta: CDC; 1994.

9. CDC - Centres for Disease Control and Prevention. Outbreak of West Nile like viral encephalitis, New York; 1999; MMWR Morb Mortal Wkly Rep 1999; 48(38): 845-9.

10. Mostahari F, Ostahari F, Bunnig ML, Kitsutani PT et al. Epidemic of West Nile encephalitis, New York, 1999: results of a household-based seroepidemiological survey. Lancet 1001; 358: 261-4.

11. Wilson ME. Travel and the emergence of infectious diseases. Emerg Infect Dis 1995: 1(2); Disponível em http://www.cdc.gov/eid
12. Garreth L. A próxima peste. Rio de Janeiro: Nova Fronteira; 1994.

13. Morse SS. Factors in the Emergence of Infectious Diseases. Emerg Infect Dis 1995; 1(1): 7-15.

14. Pattison J. The emergence of Bovine Spongiform Encephalopathy and related diseases. Emerg Infect Dis 1998; 4(3): 390-4.

15. Alterkruse SF, Cohen ML, Swedlow DL. Emerging foodborne diseases. Emerg Infect Dis 1997; 3(3): 285-93.

16. Taylor JL, Tuttle J, Pramukul T, O’Brian K et al. An outbreak of colera in Maryland associated with imported commercial coconut milk. J Infect Dis 1993; 167: $1330-5$.

17. CDC - Centres for Disease Control and Prevention. Outbreak of poliomyelitis - Dominican Republic and Haiti; 2000-2001; MMWR Morb Mortal Wkly Rep 2001; 50(08): 147-8.

18. Vasconcelos PFC, Luna EJA, Galler R, Silva LJ et al. Serious adverse events associated with yellow fever 17 DD vaccine in Brazil: a report of two cases. Lancet 2001; 358: 91-7.

19. Melker HE, Schellekens JFP, Neppelenbroek SE, Mooi FR et al. Reemergence of pertusis in the highly vaccinated population of The Netherlands: observations on surveillance data. Emerg Infect Dis 2000; 6(4): 348-57.

20. Robinson WS. Hepatitis B virus. In: Mandell GL, Benett JE, Dolin R. Principles and Practice of Infectious Diseases, 5th ed.: 1652-1685; New York: Churchil Livingstone; 2000.

21. Brazilian Purpuric Fever Study Group. Haemophylus aegyptius bacteraemia in Brazilian purpuric fever. Lancet 1987; 2: 761-3. 
22. Brenner DJ, Mayer LW, Carlone GM, Harrison LH et al. Biochemical, genetic and epidemiologic

characterization of Haemophylus influenzae biogroup aegyptius (Haemophylus aegyptius) strain associated with Brazilian Purpuric Fever. J Clin Microbiol 1988; 26: 1524-34.

23. Alibek K. Biohazard. New York: Random House; 2000.

24. Barreto ML, Carmo EH, Santos CAS, Ferreira LDA. "Emergentes", "reemergentes" e "permanecentes": tendências recentes das doenças infecciosas e parasitárias no Brasil. IESUS 1996; 5(3): 7-17.

25. Teixeira MG, Barreto M, Guerra Z. Epidemiologia e medidas de prevenção do dengue; Informe

Epidemiológico do SUS 1999; 8(4): 5-33.

26. Balter S, Benin A, Pinto SWL, Teixeira SWL et al. Epidemic nephritis in Nova Serrana, Brazil. Lancet 2000; 355: 1776 -80.

27. Drotman P. Emerging infectious diseases: a brief biographical heritage. Emerg Infect Dis 1988; 4(3):Disponível em http://www.cdc.gov/eid

28. Rappole JH, Derrickson SR, Hubalék Z. Migratory birds and the spread of West Nile virus in the Western Hemisphere. Emerg Infect Dis 2000; 6(4): 319-28.
29. Pan American Health Organization. Workshop to define priorities of institutional strengthening for the diagnostic and epidemiological surveillance of emerging diseases. Final Report. Goiania; 1996.

30. OPS - Organización Panamericana de Salud. Respuesta da la OPS al peligro de las enfermedades infeciosas emergentes y reemergentes. Rev Panam Salud Publica 2000: 7(4): 278-282.

31. Barata RCB. O desafio das doenças emergentes e a revalorização da epidemiologia descritiva. Rev. Saúde Pública 1997: 31 (5): 531-7.

32. Hugues JM. Addressing emerging infectious diseases threats - accomplishments and future plans. Emerg Infect Dis 1988; 4(3): Disponível em http:// www.cdc.gov/eid

33. Gattás VL. Doenças emergentes e reemergentes no Brasil. Documento interno/Centro Nacional de Epidemiologia (não publicado); 2000.

34. Momen H. Emerging Infectious Diseases - Brazil. Emerg Infec Dis 1988; 4(1): Disponível em http:// www.cdc.gov/eid

Recebido em 09/04/02; aprovado em 30/07/02 